\title{
Investigation of the Electromagnetic Compatibility of a Frequency-controlled Electric Drive with Supercapacitors
}

\author{
I.V. Plotnikov, ${ }^{1, *}$ and I.S. Uimin ${ }^{1}$ \\ ${ }^{1}$ Ural Federal University named after the first President of Russia B.N. Yeltsin, 620002, Mira street, 19, Ekaterinburg, \\ Russia.
}

\section{Abstract}

In the paper, the electromagnetic compatibility of a frequency converter with a power supply is investigated. Comparison of the variants of the electric drive with conventional capacitors and supercapacitors, which are connected directly to the DC link of the frequency converter, is given. The simulation results in the MATLAB package and the experimental study of the electric drive with using the power quality analyzer are presented. The paper presents the forms of currents and voltages at the input of the frequency converter, as well as their harmonics composition. Conclusions about the influence of the supercapacitor block on the electromagnetic compatibility of electric drive to the mains are made.

Keywords: Energy, Intelligent Systems, electric power industry, modelling and simulation.

Received on 31 May 2018, accepted on 05 September 2018, published on 25 October 2018

Copyright (C) 2018 I.V. Plotnikov and I.S. Uimin, licensed to EAI. This is an open access article distributed under the terms of the Creative Commons Attribution licence (http://creativecommons.org/licenses/by/3.0/), which permits unlimited use, distribution and reproduction in any medium so long as the original work is properly cited.

doi: 10.4108/eai.12-9-2018.155862

*Corresponding author. Email: yu.v.plotnikov@urfu.ru

\section{Introduction}

According to various estimations, the different types of electric drives consume about $60-70 \%$ of all the generated energy [1]. At the same time, the most modern and widely used electric drive system is a frequency-controlled electric drive. The proportion of such electric drive systems at the modern plants is quite high and is typically greater than $25 \%$.

At the same time, it is known that in addition to wellknown advantages, associated with high energy and technical-economic indicators, the frequency-controlled electric drive negatively affects on the power supply and is a source of high-frequency harmonics. This is connected with the fact that the frequency converter with an uncontrolled rectifier at the input consumes from the power supply a nonsinusoidal current in the form of pulses, which leads to a distortion in the supply voltage. And since the specific power of frequency-controlled electric drives is constantly growing, the problems of electromagnetic compatibility between frequency converters and the mains are becoming more important.

Of course, frequency converters with active voltage rectifiers do not have such drawbacks, since they consume almost sinusoidal current from the mains and the total harmonic distortion for current for them is about $5 \%[5,6]$. However, they have a significantly higher cost and their installed power at the enterprises is significantly lower in comparison with converters with a bridge uncontrolled rectification circuit at the input, the total current distortion factor for which can exceed $60 \%$, even when using smoothing reactors [6].

The problem of electromagnetic compatibility of a frequency-controlled electric drive with a power supply network has been well studied and the main solutions for reducing the influence of frequency converters to the mains have been well developed, starting from the using of filters at the input and ending with active semiconductor filters [58]. The purpose of this work is to analyze the influence of the electric drive with supercapacitors on the power network and compare its effect with conventional frequency converters. 


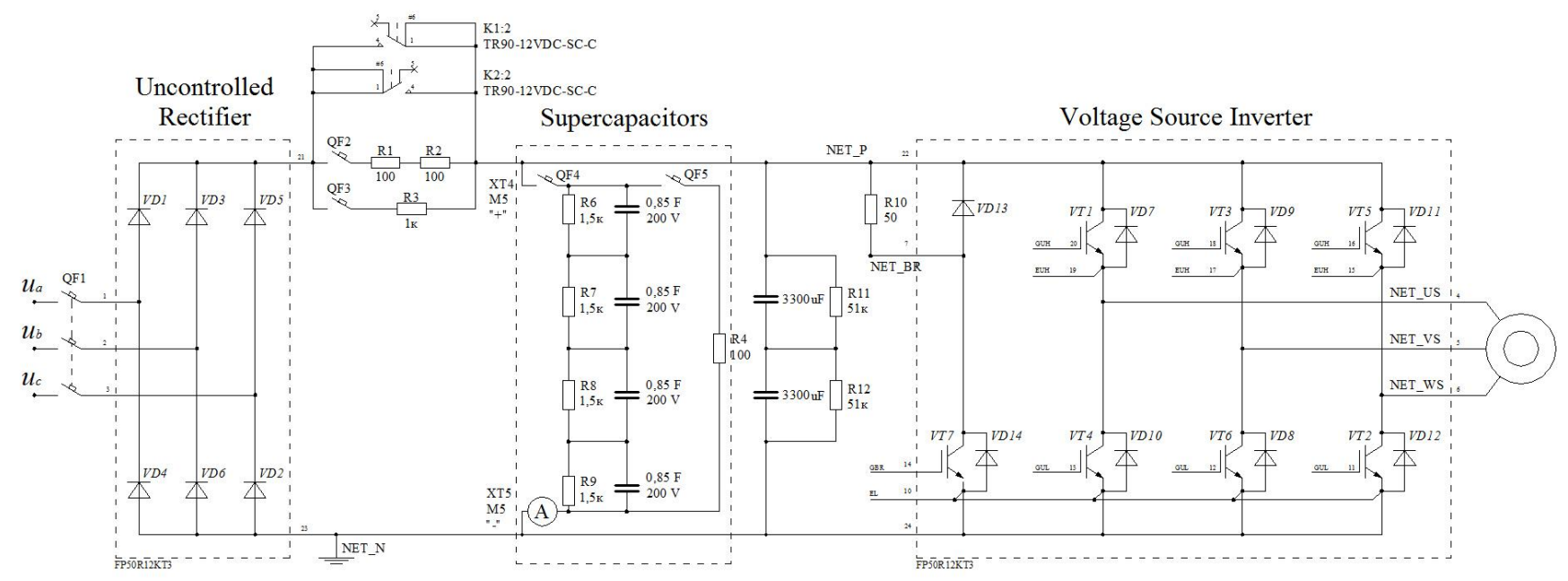

Figure 1. Functional diagram of frequency converter with supercapacitors block

The block of supercapacitors in a frequency-controlled electric drive increases its energy efficiency, which leads to a reduction in the energy consumption of the electric drive up to $50 \%$ in comparison with solutions, in which the braking energy is dissipated on the braking resistor [13]. Another important advantage of such electric drive systems is the increasing the system autonomous work time during the power supply failure, especially if together with supercapacitors the batteries are used. And since such solutions are used in regions with weak mains, or with autonomous power supply, the problem of electromagnetic compatibility becomes more important.

The article considers a variant, where the supercapacitors are connected directly to the DC link of the frequency converter. Although this version has several disadvantages, associated with incomplete using of the capacitance of the supercapacitor, however this is the simplest and inexpensive solution, which does not require the using of additional DC-DC converters with its own automatic control system [3].

Schematic diagram of this connection is shown in Figure 1. In the frequency converter, which will later be used for experimental investigations, four seriesconnected super-capacitors with a rated voltage of $200 \mathrm{~V}$ and a capacitance of $0.85 \mathrm{~F}$ are connected directly to the DC link of the frequency converter in parallel with the existing capacitors.

For the charging the supercapacitors, the charging circuit of the frequency converter, which protects the uncontrolled rectifier at the input from overcurrent, has been changed. It is important to note that the capacitance in the DC link of the frequency converter in this case has increased more than 150 times and the aim of this study is to determine the influence of the supercapacitor block on the electromagnetic compatibility of the electric drive with the power supply.

\section{Simulation results}

At the first step, the electric drives system with conventional and supercapacitors, connected to the DC link of the frequency converter, was simulated. In the simulation, an induction motor with a rated power of 3 $\mathrm{kW}$ was used, which will then be used in the experimental setup. To power the motor, a frequency converter with an uncontrolled rectifier at an input and rated power of 10 $\mathrm{kW}$ with a scalar, open-loop automatic control system, was used. The active resistance of the power supply during the simulation was selected in accordance with the parameters of the experimental setup, which is powered from an alternating current network with an internal active resistance about 3.4 Ohm. During the simulation the smoothing reactors with an inductance of $2.26 \mu \mathrm{H}$, which are used in the experimental setup, were included in the input circuit of the frequency converter.

To estimate the influence of the frequency converter with supercapacitors to mains, the quality of the supply voltage was analyzed for compliance with standard (GOST 32144-2013 [4]). Standard regulates two indicators, which relate to the distortion of the supply voltage form. The content of each harmonic is regulated separately up to the 40th and the total distortion coefficient of the voltage waveform, which shows the resultant effect of all harmonics on the shape of the voltage. The standard regulates the content of each harmonic separately up to 40 and the total harmonic distortion of the voltage waveform, which shows the resultant effect of all harmonics on the voltage form [4].

One must mention that the form and harmonic composition of the input currents of frequency converter gives more information about how much the converter distorts the power supply voltage. However, this indicator is not regulated by the standard, since the voltage distortion depends not only from the harmonic 
composition of the current and its form, but it also depends from the current magnitude and from the internal resistance of the power supply.

Harmonic measurements and the quality estimation of supply voltage were carried out after the starting electric drive with load about $75 \%$ from the rated motor torque.

The Fig. 2 shows the currents waveform at the input of the frequency converter in the steady state mode.

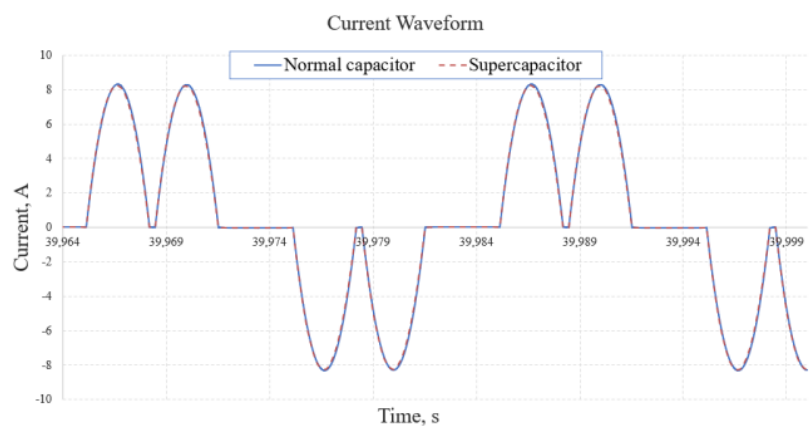

Figure 2. Current waveform on the input of frequency converter

From the figure we can see that the electric drive consumes a substantially non-sinusoidal current from the mains, which does not change significantly when a supercapacitors block is connected to the DC link. These results are confirmed by the harmonics composition of the input currents, which is shown in Fig. 3.

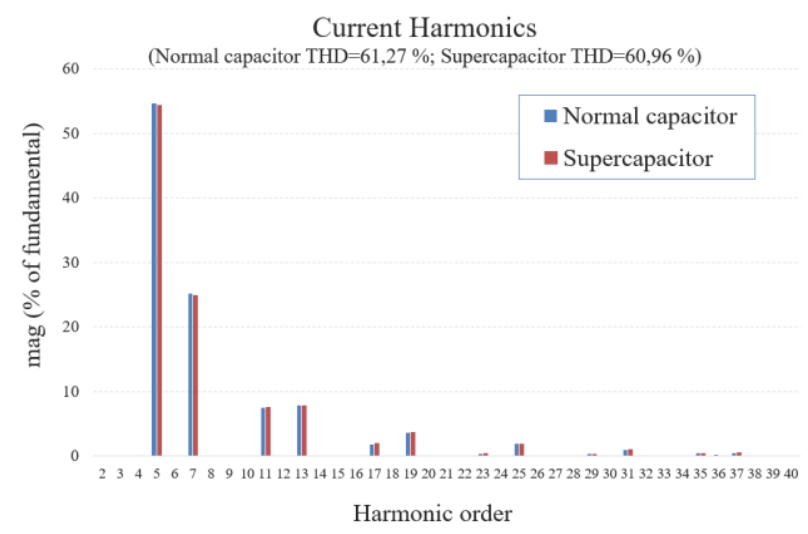

Figure 3. Input current harmonics

THD in the input currents of the converter in both cases differs not significantly and it is slightly more than $60 \%$, which obviously will negatively affect to the mains voltage. The same conclusions can be done about the harmonics composition of the input currents, which has hardly noticeable differences for the electric drive with conventional and supercapacitors.

This is explained by the fact that despite on significantly lower voltage pulsations in the DC link of the frequency converter during the using of supercapacitors, the shape of DC link voltage does not change significantly (see Fig. 4). And since the frequency converter consumes current from the power supply at those times when the voltage on the capacitor becomes less than the voltage at the output of the uncontrolled rectifier, the same form of voltage in the DC link allows us to conclude that the using of supercapacitors instead of conventional capacitors does not significantly affects on the distortion of the supply voltage.

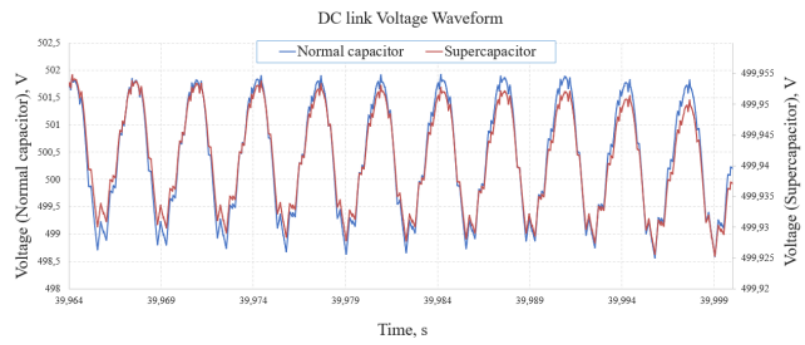

Figure 4. Voltage in the DC link of frequency converter

The harmonic composition of the voltage at the converter input is shown in Fig. 5. As we can see from figure the frequency converter, which operates with an almost rated load distorts the voltage of the mains.

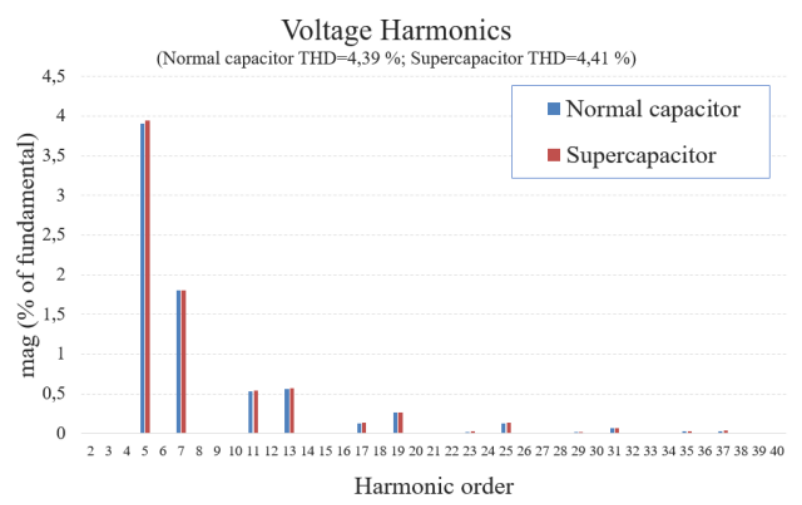

Figure 5. Input voltage harmonics

However, all the network quality indicators comply with the Russian standard. So, voltage THD for both cases is about $4 \%$, while for a voltage of $380 \mathrm{~V}$, the normally acceptable value in standard is $8 \%$, and the maximum permissible value is $12 \%$ [4]. Similar conclusions can be done from the voltages harmonics, where the most disadvantageous are the 5th and 7 th harmonics, the level of which is about 4 and $2 \%$ respectively, while the standard allows normal admissible values of 6 and $5 \%$.

Therefore, based on the simulation results, we can make a preliminary conclusion that the using of supercapacitors does not have a stronger negative influence on the power supply compared to frequency converters with conventional capacitors.

\section{Experimental results}

The next task was to carry out a series of experimental investigations of the electromagnetic compatibility a 
power supply and frequency-controlled electric drive with supercapacitors. Functional diagram with direct connection of supercapacitors to DC link of frequency converter was presented in Fig. 1.

The block of the supercapacitors is connected to the DC link of the frequency converter by means of the circuit breaker QF4. When this breaker is in off position we will get a standard frequency converter. The functional diagram of the experimental setup is shown in Fig. 6.

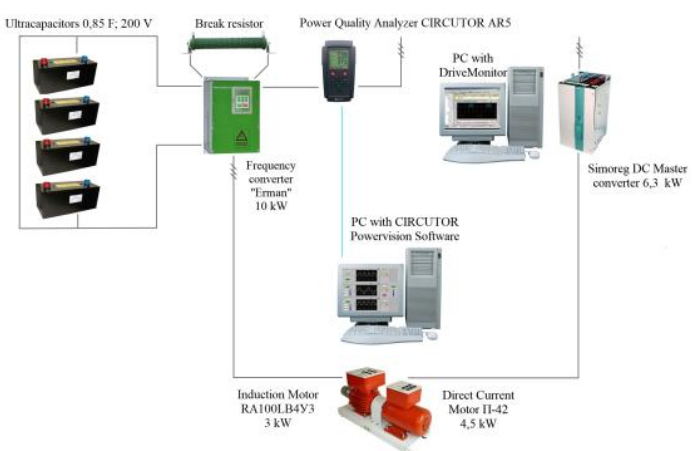

Figure 6. Functional diagram of experimental setup

For the analysis of electromagnetic compatibility, the AR5 quality analyzer together with the personal computer, on which the specialized software CIRCUTOR Powervision is installed, was used. The device has a wide range of functions and allows to measure harmonics of currents and voltages with automatic calculation of THD for each measuring point.

The frequency converter is connected to an induction motor, on one shaft with which a DC motor is mounted. The DC motor is used to create a load on the induction motor shaft. The DC motor is powered by a Simoreg DC Master thyristor converter, which operates in the current control mode. The measurements were carried out in a steady state operation mode with a load of about $75 \%$ from the nominal value.

Figures 7 and 8 clearly show the negative influence of the frequency converter on the mains.

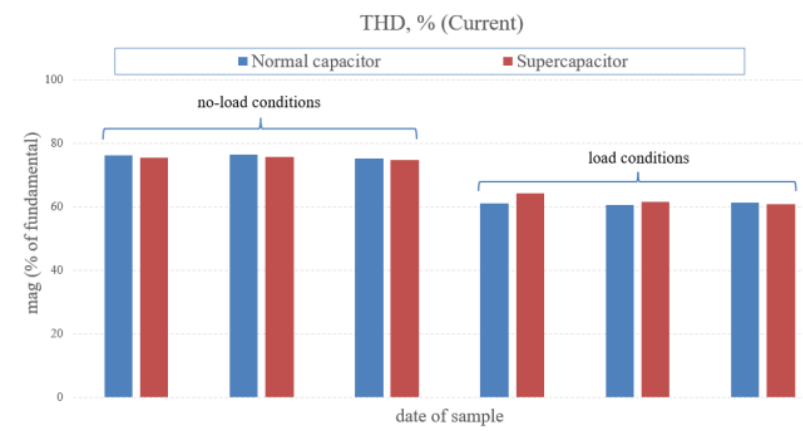

Figure 7. Influence of the converter load on the current THD

In Fig. 7 shows a series of current THD points before and after applying the load to the electric drive. Although the current form after the load applying has less distortion, as indicated by the total harmonics distortion, the effect of the converter on the network has become more significant.

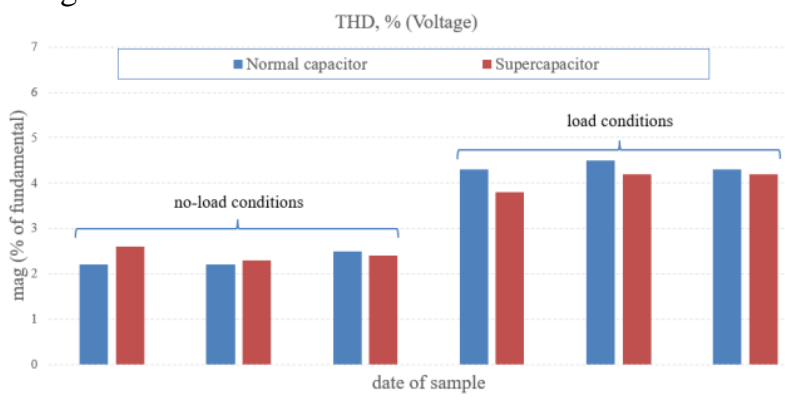

Figure 8. Influence of the converter load on the voltage THD

Figure 8 , which illustrates a series of voltage points THD at the same times as in Fig. 7, shows that when the load applied to the motor shaft, the voltage THD is increased from 2 to $4 \%$. This is connected with the fact that the amplitude of non-sinusoidal current is significantly increased, which led to an increasing in distortion of the mains voltage.

Figure 9 shows the currents waveform at the input of the frequency converter with a conventional capacitor and with supercapacitor. Differences in the form of the currents during using the supercapacitors are not significant, which is agreed with the simulation. Fig. 10, which shows current harmonics, also shows that the influence of supercapacitors on the power supply is not significant, compared to "normal" capacitors in the DC link of frequency converter.

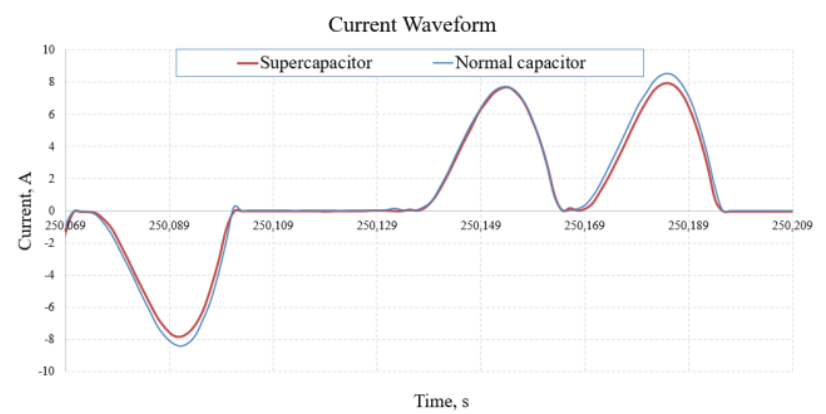

Figure 9. Current waveform on the input of frequency converter

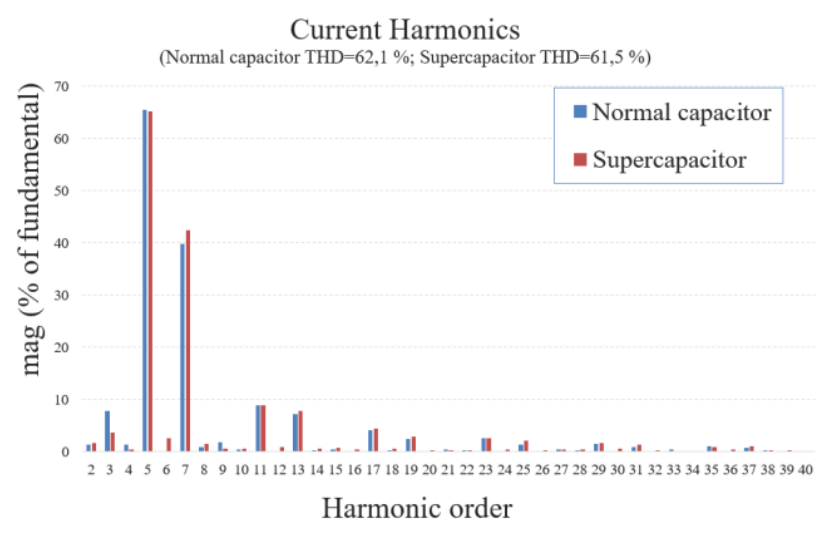

Figure 10. Input current harmonics 
One must mention, that the harmonic composition of the input currents and its waveform has some slight differences from the simulation results (See Fig. 3), which is connected with the fact, that the simulation does not accurately account all factors, affecting on the form of the input currents.

In Fig. 11 shows the form of the supply voltage on a part of the power supply period, which can be displayed by means of an energy quality analyzer.

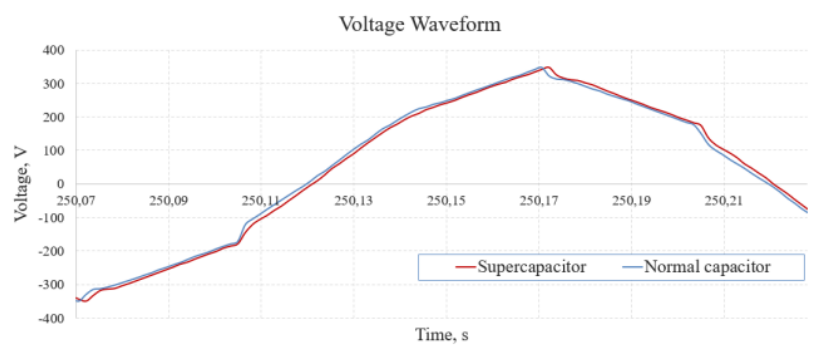

Figure 11. Voltage waveform on the input of frequency converter

In the form of voltage, we can see the distortions, caused by the connection to the network of a frequencycontrolled electric drive. As in previous cases, the distortion results for the drive with supercapacitors are practically the same as for the electric drive with conventional capacitors, which is also confirmed by the harmonics of the power supply voltages, which are shown in Fig. 12.

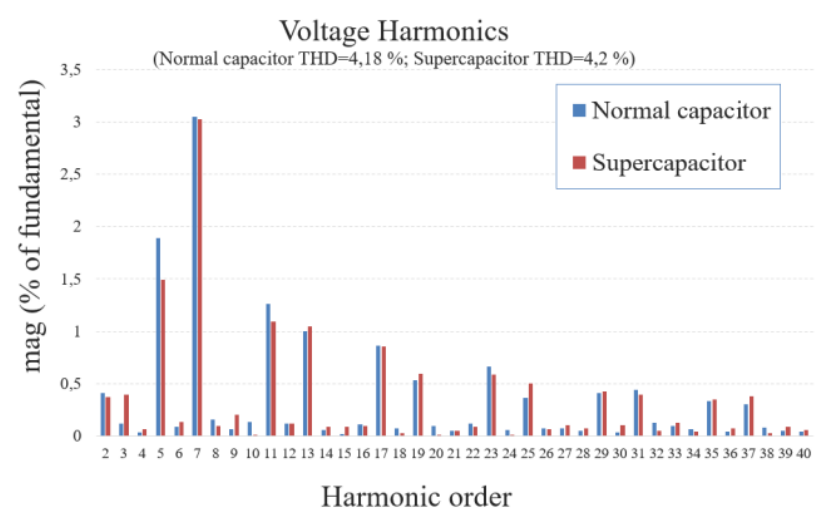

Figure 12. Input voltage harmonics

\section{Conclusions}

It is known that the using of supercapacitors in a frequency-controlled electric drive leads to a significant reduction in power consumption in comparison with an electric drive, where the braking energy dissipates on the external resistance. At the same time, the constantly growing specific power of semiconductor converters at enterprises forces to pay more attention to the problem of electromagnetic compatibility of semiconductor converters with a power supply.
The results of simulation and experimental investigations show that the direct connection of supercapacitors to the DC link of the frequency converter does not have a more significant influence on the power supply compared with electric drive with conventional capacitors. This is explained by the fact, that the voltage form in the DC link of the converter with the supercapacitor, in spite of the significantly lower level of pulsations, has almost the same form as in the frequency converter with conventional capacitors.

In order to reduce the influence of the electric drive with supercapacitors on the power supply, it is possible to use the same measures that are used for traditional electric drives, such as the installation of smoothing reactors at the input or in the DC link of frequency converters.

\section{References}

[1] Braslavsky I.; Ishmatov Z.; Plotnikov Y., Erman G. (2012) About the using of capacitive energy storages in the frequency-controlled electric drives. Proceeding of Symposium on Power Electronics, Electric Drives, Automation and Motion. Taormina, (Italy), 2012. pp. 920925.

[2] I. Braslavsky, I. Plotnikov, Z. Ishmatov, F. Polunin. (2014) The Estimation of Technical and Economic Efficiency of Using the Supercapacitors in the Hoisting Applications. Proceeding of Symposium on Power Electronics, Electric Drives, Automation and Motion. Ischia, (Italy), 2014. pp. 179-183.

[3] Ishmatov, Z., Plotnikov, I., Braslavsky I. (2016) About application perspective of capacitive energy storage in the frequency-controlled electric drive. 9th International Conference on Power Drives Systems, ICPDS 2016, pp. 123-127.

[4] GOST 32144-2013 (2014), Electric Energy. Compatibility of technical equipment. Quality standards of electricity in utility power systems, Standartinform, 2014.

[5] V. Meshcheryakov; A. Evseev; A. Boikov (2018). Active energy filter for compensation of harmonic distortion in motor soft starter. 2018 17th International Ural Conference on AC Electric Drives (ACED), pp. 1-5.

[6] F. B. Libano; R. A. M. Braga; L. N. de Souza (2002). Introduction to electromagnetic compatibility in invertedfed induction motor drives. 10th International Conference on Harmonics and Quality of Power. Proceedings (Cat. No.02EX630). Volume: 2. pp: $770-775$.

[7] I. I. Artyukhov; I. I. Bochkareva; S. V. Molot (2014). Assurance of electromagnetic compatibility of group frequency controlled electro drives with power supply sources. 2014 International Conference on Actual Problems of Electron Devices Engineering (APEDE). Volume: 2. pp: $11-17$.

[8] S.P. McDonald ; N. Wade ; I. Cooper ; N. Heyward ; I. Morgan ; M. Madera (2016). Electromagnetic compatibility for large scale Electrical Energy Storage. 8th IET International Conference on Power Electronics, Machines and Drives (PEMD 2016). pp: $1-6$. 